\title{
Sexual and reproductive health needs of adolescents perinatally infected with HIV in Uganda
}

\author{
Harriet Birungi \\ Population Council \\ John Frank Mugisha \\ Juliana K. Nyombi \\ Francis Obare \\ Population Council \\ Humphres Evelia \\ Population Council
}

See next page for additional authors

Follow this and additional works at: https://knowledgecommons.popcouncil.org/departments_sbsr-rh

Part of the International Public Health Commons, Maternal and Child Health Commons, Medicine and Health Commons, Obstetrics and Gynecology Commons, Virus Diseases Commons, and the Women's Health Commons How does access to this work benefit you? Let us know!

\section{Recommended Citation}

Birungi, Harriet, John Frank Mugisha, Juliana K. Nyombi, Francis Obare, Humphres Evelia, and Hannington Nyinkavu. 2008. "Sexual and reproductive health needs of adolescents perinatally infected with HIV in Uganda," FRONTIERS Final Report. Washington, DC: Population Council. 


\section{Authors}

Harriet Birungi, John Frank Mugisha, Juliana K. Nyombi, Francis Obare, Humphres Evelia, and Hannington Nyinkavu 


\section{Sexual and reproductive health needs of adolescents perinatally infected with HIV in Uganda}




\title{
Sexual and reproductive health needs of adolescents perinatally infected with HIV in Uganda
}

\author{
Harriet Birungi ${ }^{1}$, John Frank Mugisha ${ }^{2}$, Juliana Nyombi ${ }^{2}$, \\ Francis Obare ${ }^{3}$, Humphres Evelia ${ }^{1}$, and Hannington Nyinkavu ${ }^{2}$ \\ ${ }^{1}$ Frontiers in Reproductive Health (FRONTIERS), Population Council \\ ${ }^{2}$ The AIDS Support Organization (TASO), Uganda \\ ${ }^{3}$ Bixby Fellowship Program, Population Council
}

July 2008

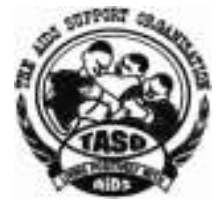




\section{Acknowledgements}

Many people and organizations contributed to the conceptualization, development, implementation and completion of this research. USAID and the Ford Foundation provided financial support. Participants in the three stakeholder-meetings (i.e. the consultative workshop, the data interpretation meeting and the results dissemination workshop), especially Dr. Emmanuel Luyirika, Dr. Ekie Kikule and Ms. Irene Kambonesa of Mildmay Centre, Kampala, contributed ideas and raised issues that greatly shaped the direction of the study.

We are also indebted to Dr. Alex Coutinho (former Director TASO), Mr. Nicholas Mugumya (Deputy Executive Director, TASO), all managers and staff of the TASO branches in Entebbe, Jinja, Masaka and Mulago, as well as to other HIV/AIDS treatment and care support centers (Mildmay Centre, Uganda Cares Masaka, Nsambya Home Care, Mengo Home Care, Rubaga Home Care, Villa Maria Home Care, and the AIDS Information Centre (AIC) in Kampala and Jinja) for opening their doors to the research team. TASO Central Region provided office space for the research coordination unit. Ethical clearance for the study was granted by the TASO Internal Review Board (IRB), the Uganda National Council of Science and Technology (UNCST), the Population Council's Institutional Review Board and the District Health Officers for Jinja, Masaka, Kampala and Wakiso.

We are most grateful to our informants: program managers, service providers, young people living with HIV and their parents/guardians for their invaluable support to the project. The successful completion of the study was also made possible by the dedicated team of researchers: Linda Kavuma (Program reviewer); Lillian Mpabulungi, Christine Obbo and Lynda Nakalawa (Ethnographers), Research Assistants and translators (Joy Gumikiriza, Victor Guma, Doreen Kayongo, Mike Lukundo, Yonna Mutekanga, Yudaya Nabukeera, Lynda Nakalawa, Sumaya Nakazibwe, Godlove Nantumbwe, Jonathan Ngobi, Rahma Mutesi, Robert Ssajabi and Clyde Ssembusi). Paul Ssengooba along with his team of data entry personnel including Jacob Ssenkungu, assisted with data management.

This study was made possible by the generous support of the American people through the United States Agency for International Development (USAID) under the terms of Cooperative Agreement No. HRN-A-00-98-00012-00 (Subagreement No. SI07.009A and In-house project No. 5800 53112) and by the support of the Ford Foundation (contract No. 1070 - 0231). The contents are the responsibility of the FRONTIERS Program and do not necessarily reflect the views of USAID, the United States Government or the Ford Foundation.

Published in July 2008

(C) 2008 The Population Council

Suggested citation: Birungi H., Mugisha JF., Nyombi J., Obare F., Evelia H., and Nyinkavu H. 2008. Sexual and reproductive health needs of adolescents perinatally infected with HIV in Uganda. FRONTIERS Final Report. Washington DC, Population Council. 


\section{Table of Contents}

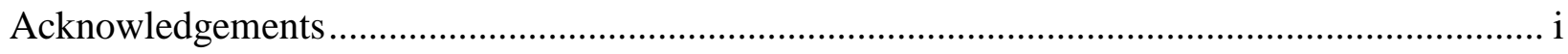

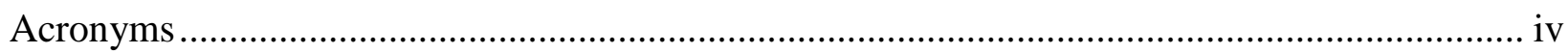

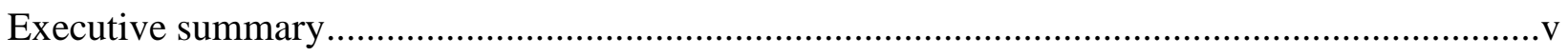

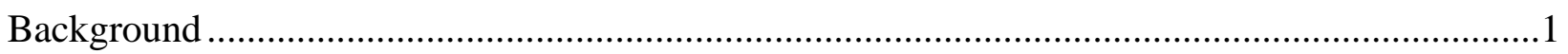

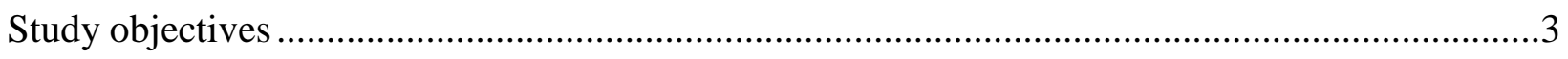

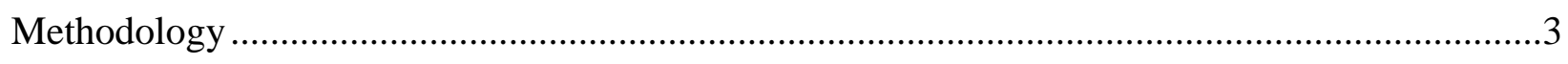

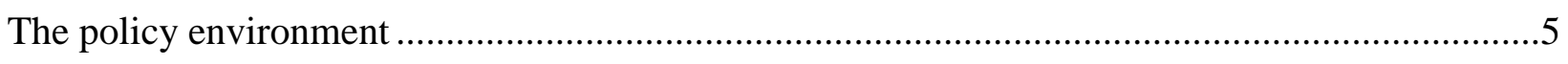

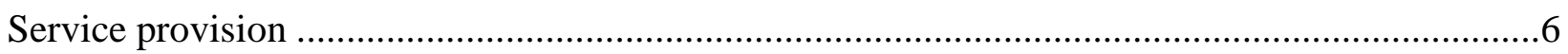

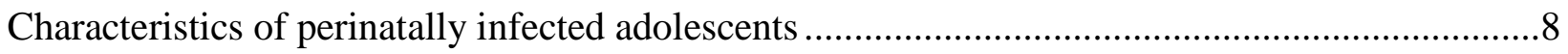

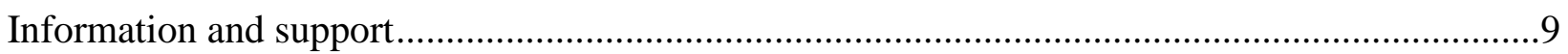

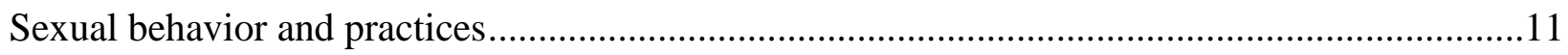

Preventive knowledge and practices .............................................................................. 12

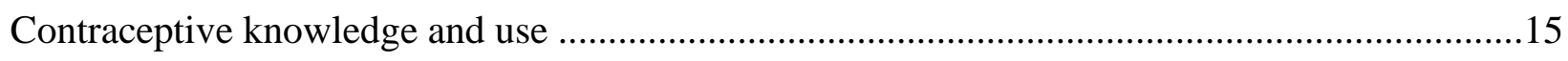

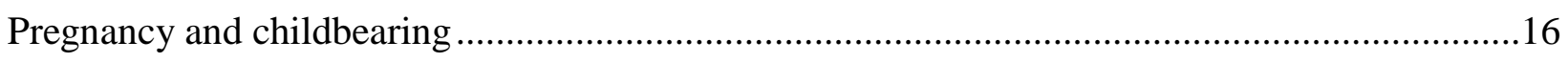

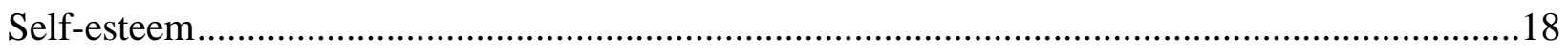

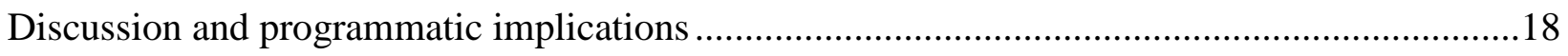

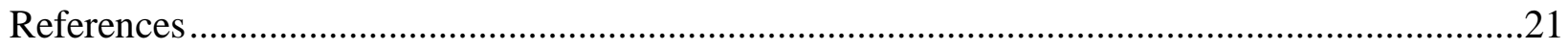




\section{List of Tables}

Table 1: HIV/AIDS treatment, care and support centers/facilities visited in each

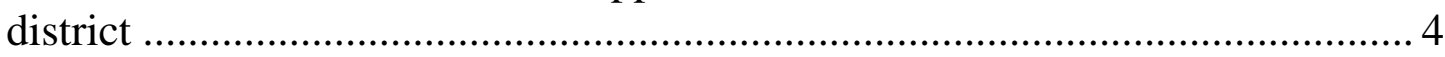

Table 2: List of key informants by institutions .......................................................... 5

Table 3: Distribution of survey respondents by other background characteristics ............ 8

Table 4: Percentage of respondents who ever talked with parents/guardians and

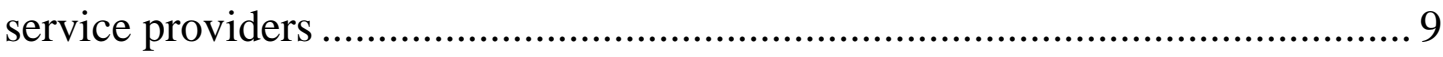

Table 5: Percentage of respondents who have ever engaged in particular sexual

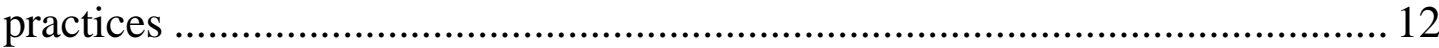

Table 6: Knowledge of ways of preventing re-infection with HIV and pregnancy........ 13

Table 7: Percentage of respondents who used a method to prevention of HIV infection or pregnancy .................................................................................... 13

Table 8: Percentage of respondents who knew of a method of contraception................. 15

Table 9: Percentage of sexually active young people by pregnancy experience and

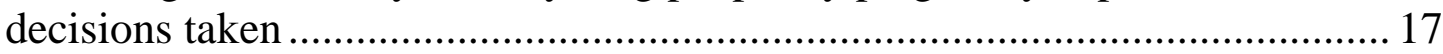

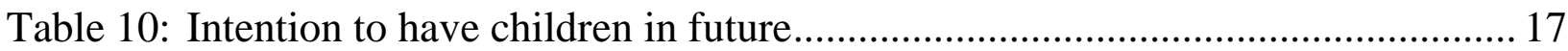

Table 11: Percent distribution of respondents worried about various aspects of life ....... 18

\section{List of Figures}

Figure 1: Percentage of respondents who belong to particular types of support groups ...............10

Figure 2: Distribution of respondents by whether they are currently in sexual partnership..........11

Figure 3: Distribution of respondents who had disclosed their HIV sero-status to significant others

Figure 4: Distribution of respondents who used any method of contraception in current or previous relationship and the frequency of current use. 


\section{Acronyms}

AIC

AIDS

ART

EC

FP

HIV

IRB

MGLSD

$\mathrm{MoH}$

NGOs

OGMAC

PEARL

PIDC

PLHA

PMTCT

SCOT

SGBV

SPSS

SRH

STD

STI

TASO

UBOS

UDHS

UNCST

UNFPA

UNICEF

UYDE

WHO
AIDS Information Centre

Acquired Immunodeficiency Syndrome

Antiretroviral Therapy

Emergency contraception

Family Planning

Human Immunodeficiency Virus

Internal Review Board

Ministry of Gender, Labour and Social Development

Ministry of Health

Non-Governmental Organizations

Our Generation of Mildmay Adolescents Clients

Program for Enhancing Adolescent Health

Pediatric Infectious Disease Clinic

Person Living with HIV/AIDS

Prevention of Mother to Child Transmission

Strengthening Counselor Training

Sexual and gender-based violence

Statistical Package for Social Sciences

Sexual and Reproductive Health

Sexually Transmitted Diseases

Sexually Transmitted Infections

The AIDS Support Organization

Uganda Bureau of Statistics

Uganda Demographic and Health Survey

Uganda National Council of Science and Technology

United Nations Fund for Population Activities

United Nations Children's Fund

Uganda Youth Development Link

World Health Organization 


\section{Executive summary}

The rapid roll-out of anti-retroviral treatment programs has made it possible for perinatally infected infants to live through adolescence and adulthood, thereby engaging in dating and sexual relationships. However, the sexual and reproductive health needs of this unique and rapidly increasing population are largely unmet. In Uganda, the HIV/AIDS treatment, care and support programs are still organized around either adult or pediatric care and fail to adequately address the needs of this growing segment of the population that usually falls between these two groups. Most programs assume that HIV-infected young people remain asexual. Service providers and counselors usually advise perinatally infected adolescents not to engage in sexual relationships.

This study, implemented jointly by the Population Council's Frontiers in Reproductive Health (FRONTIERS) program and the AIDS Support Organization (TASO) with funding from USAID and the Ford Foundation, involved qualitative research and a survey of 732 perinatally HIVinfected girls and boys aged 15-19 years in four districts of Uganda (Kampala, Wakiso, Masaka and Jinja). Its aim was to better understand the reproductive health and sexuality (desires, experiences, beliefs, values and practices) of this population group, and to identify anxieties or fears they have around growing up, love and loving, dating, pregnancy, fatherhood, motherhood, relationships and intimacy that could be addressed through programmatic solutions tailored to their unique needs.

\section{Key findings}

Perinatally infected adolescents are sexually active: Fifty two percent of the respondents were currently in a relationship, 33 percent reported having had sexual intercourse and of these, 73 percent had consensual first sex. Forty four percent of those not sexually active reported a desire to have sex while 41 percent felt that there is no reason why someone who is living with HIV should not have sexual intercourse.

Poor preventive practices among the adolescents: Among those who had ever had sex, only about one-third (37 percent) reported using a method to prevent HIV infection or re-infection at first sex. Similarly, only $30 \%$ of those who reported current use of condoms were using them explicitly to prevent infecting their partner with HIV/STDs. Just over one-third disclosed their HIV status to their partners (38 percent). Disclosing sero-status was one of the greatest fears of the adolescents (51 percent feared disclosing their status to friends). Qualitative data however, suggested that even in the event of disclosure, the partners do not mind having or continuing the relationship, even if they are discordant.

Strongly desire to have children, but in the future: 41 percent of the sexually active female adolescents had ever been pregnant, almost three-quarters of them kept the pregnancy and more than two-thirds (69 percent) of the adolescents who already had children intend to have more in the future. More than four-fifths ( 86 percent) of those who did not have children intend to do so later in life. 
Parents and guardians rarely talk to the adolescents about sexuality: Only about one-third $(35 \%)$ of adolescents reported having ever talked with their parents/guardians about dating and sex. Another one-third talked with parents about how pregnancy occurs and about a method of birth control. Adolescents seem more comfortable talking with parents and guardians about fear (66\%), hopes (70\%) and living life as a young person (63\%). In contrast, adolescents are more likely to talk to service providers/counselors than their parents/guardians about sexuality issues more than $50 \%$ of the adolescents reported talking to providers/counselors about dating, how pregnancy occurs, contraception, and sex.

HIV positive adolescents construct their lives positively: Not many worry about being HIV positive. They have much hope for the future and the majority (65 percent) would like to be professional scientists, medical doctors, lawyers and entrepreneurs. Almost half (46 percent) want to be well-educated and to prosper in future and look forward to achieving these dreams. Worries about illness, on the other hand, revolve around disclosing their HIV status to friends, people finding out that they live with HIV, and infecting someone else with HIV.

\section{Programmatic implications}

Strengthen preventive services: Sexually active HIV positive adolescents need appropriate information to prevent unintended pregnancies and HIV transmission. Therefore, HIV/AIDS treatment centers that provide care and support will need to improve their access to information and services for family planning and HIV prevention. HIV positive adolescents need information to be able to negotiate disclosure, dual protection, and consistent condom use. The findings suggest that adolescents would prefer seeking contraceptive services from HIV/AIDS care and treatment centers. Therefore, such programs need to strengthen provision of family planning (FP) services by assessing the contraceptive needs of adolescents and making available an appropriate method mix in a non-judgmental and supportive way.

Making pregnancy safer for HIV positive adolescents: 13 percent of female HIV positive adolescents have experienced a pregnancy (our study did not investigate their pregnancy outcomes). This notwithstanding, effective PMTCT services are critical for this group. In particular, HIV/AIDS treatment centers should be able to identify pregnant adolescents early and ensure that they receive a full range of PMTCT and other antenatal care services in order to avoid transmitting HIV to their babies. This group should be enabled to receive skilled attended birth at delivery and postpartum family planning and HIV services.

Involve parents to openly discuss sexuality: The findings show that parents and guardians rarely talk to the adolescents about their sexuality. Programs will need to test interventions that encourage and enable parents and guardians to open up and discuss these issues with their adolescents.

Re-orient service providers/counselors: Whereas service providers/counselors are more likely to talk about sexuality than parents and guardians, service providers tend not to offer balanced counseling. They tend to providing only warnings about the potentially adverse outcomes of sex instead of providing practical information, guidance and support to the young people. They also tend to develop a parent-child relationship with the adolescents during counseling, to the extent that the adolescents fear disclosing to them not only their sexual behaviors and desires, but also pregnancies when they occur. Programs need to provide training and reorientation to help 
providers/counselors execute their work without becoming "parents". HIV/AIDS counselors would benefit from an adolescent "sexuality or fertility" assessment tool that they can use as a checklist for relevant items to discuss with HIV positive adolescents during counseling encounters. The tool could help the provider/counselor to systematically assess adolescents for their sexual and reproductive health information and service needs and to address them immediately and/or offer appropriate referral. In addition, existing counseling and support training packages for HIV positive individuals need to be updated to include vital information on the sexual and reproductive health needs of HIV positive adolescents.

Establish transition clinics: Some of the care centers are not age-sensitive as they bring together children from the age of eight to 17 years. Some of the adolescents transiting to early adulthood are not yet comfortable obtaining services from the adult care centers, but they no longer fit in the pediatric clinic setting. HIV/AIDS treatment centers should therefore consider setting up transition clinics that are adolescent-friendly to cater for these young adults.

Strengthen support groups: Many HIV positive adolescents already belong to support groups, which means that these groups are a potential avenue where they can obtain critical sexual and reproductive health information and services. However, the findings also suggest that many existing support groups and clubs are weak. Programs will need to provide training to leaders of the key support groups for them to become sustainable and responsive to these needs of the members.

Improve life skills for HIV positive adolescents to: 1) understand their sexuality as they grow; 2) practically deal with the identity of being HIV positive at an early age and negotiate vital aspects of their lives, especially disclosing their status; 3 ) enjoy positive lifestyles and avoid undesired consequences such as unintended pregnancies and infection of others; and 4) make informed choices and balance responsibility with sexual and reproductive desires. This strategy could be implemented through school-based programs, care and support NGOs, support groups, etc.

In conclusion, adolescents perinatally infected with HIV have the same aspirations as those who are not HIV-infected. This study confirms that wide programmatic gaps exist in addressing the sexual and reproductive health needs of young people perinatally infected with HIV who are now growing into sexually active adolescents and adults. This evidence provides a concrete basis for generating discussions on how existing HIV/AIDS programs will have to change to provide young people with information and services. 


\section{Background}

The number of African children living with HIV continues to escalate despite the advances made in prevention of mother to child transmission (PMTCT). Ninety percent of the estimated three million children living with HIV live in sub-Saharan Africa (RCQHC 2003). In Uganda, HIV prevalence among children whose mothers are HIV positive is still very high (10 percent). Whereas previously it was never anticipated that infants born with HIV would have the opportunity to live on to adulthood and sexual development, the roll out of treatment programs has made this possible, albeit for a small but growing proportion. True numbers of living children and adolescents ${ }^{1}$ born HIV positive are almost impossible to find, but some indications are available. For instance, the oldest surviving HIV perinatally infected client of the AIDS Support Organization (TASO) in Uganda turned 25 years this year. TASO has also registered 4,696 adolescents living with HIV since infancy. The Pediatric Infectious Disease Clinic (PIDC) in Mulago hospital, Kampala, serves over 500 adolescents living with HIV, of whom 95 percent were perinatally infected. Given the rapidly improving access to ART for infants and children and the slow expansion of effective PMTCT services, the population of perinatally infected adolescents is expected to grow rapidly over the next few years.

As with all adolescents, many of those that are HIV positive are beginning to explore their sexuality - they are dating and some of them are beginning to have sex. During 2006 alone, TASO and PIDC reported 184 and 7 pregnancies respectively among young HIV positive people receiving services. It is unclear whether these pregnancies were intended or unintended. This notwithstanding, HIV infection seems not to have significantly changed attitudes towards childbearing in Uganda (Kirumira 1996). Moreover, the desire to have children early in adult life remains strong, including for people living with HIV and AIDS (PLHA), and a romantic relationship is commonly not considered legitimate unless it produces a baby. Generally, Ugandans have their first sexual experience early in life. According to the 2004-2005 HIV/AIDS Sero-Behavioral Survey (MOH and ORC Macro 2006), 14 percent of young women and men have sex before they turn age 15 , and 63 percent of women and 47 percent of young men have sex before age 18. Thus in this context, adolescents living with HIV may desire and/or succumb to familial/social pressure to have children early so that they do not die without an offspring. However, existing HIV care and support programs do not seem to address the fertility aspirations or desires of this small but rapidly growing population of adolescents.

The difficulties of working with adolescents in general on issues of sexual and reproductive health are made even more complex for adolescents living with HIV. Key interventions to alter disease transmission and prevention of pregnancy among adolescents have tended to emphasize delaying sexual debut, reducing the number of sexual partners, and increasing correct and consistent condom use. A major limitation however, is that these interventions have tended to focus on the general population, which is assumed to be either HIV negative or unaware of their HIV status. The absence of targeted research on the fertility intentions and/or sexual and reproductive health needs of adolescents living with HIV has rendered this impossible. While some existing HIV/AIDS treatment centers in Uganda are now beginning to offer family planning, these services tend to target HIV positive adults.

\footnotetext{
The term adolescent refers to people between the ages 10 -19 years (see United Nations Population Fund, 1998. The Sexual and Reproductive Health of Adolescents. Technical and Policy Division Report)
} 
In addition, if sexual and reproductive health is discussed during counseling of young HIV positive clients it tends to focus on delaying sexual initiation. Service providers seem neither interested, nor motivated or prepared to find out whether these clients are sexually active. Thus, issues related, for instance, to fertility intentions, are not given due attention, often leaving sexually active adolescents living with HIV un-prepared and unable to negotiate contraceptive use or even to access contraceptive methods.

Studies conducted elsewhere show that at least 27 percent of adolescents with perinatally acquired HIV were sexually active (Fielden et al 2006). Other studies also reveal that the prevalence of unprotected sex among HIV positive young people has increased. A study in the US that included samples of HIV positive youth aged 13-24 after the advent of highly active antiretroviral therapy showed that they were more likely to have unprotected sex with a partner they knew was HIV positive (Rice et al 2006). Anecdotal evidence from TASO Uganda ${ }^{2}$ and from South Africa suggests that most HIV positive individuals are likely to seek sexual relationships amongst themselves, and thus are more likely to have unprotected sex. This emerging evidence reinforces the need to fully understand the nature and expectations of relationships among adolescents living with HIV and their implications for sexual and reproductive health information and services, especially for those who are sexually active.

Recent WHO/UNFPA guidelines on care, treatment and support for women living with HIV/AIDS and their children in resource-constrained settings have underscored the need to address the particular sexual and reproductive health needs of adolescent girls with HIV, ensuring the availability of age-appropriate information and counseling on sexual and reproductive health and safer sexual practices, and offering family planning counseling and services that are adolescent-friendly (WHO 2006). A study in Canada (Fielden et al 2006) reinforces the importance of healthy sexual development for young people with perinatallyacquired HIV maturing into adolescence and adulthood and highlights a need for supportive policies and services, especially around family planning and partner notification.

HIV/AIDS treatment, care and support programs in Uganda and elsewhere in the Africa region will need to provide HIV positive adolescents with information and practical support to make decisions about their fertility, negotiate vital aspects of their lives, avoid undesired consequences like unwanted pregnancies, infection of others and self re-infection. There is also need to develop integrated counseling strategies that emphasize dual protection and family planning. Providers will need to understand the reasons why adolescents living with HIV may or may not choose to have children and to tailor their counseling client's needs, perceptions and circumstances. Effective counseling should also be provided so that adolescents living with HIV can make informed choices and be able to balance responsibility with sexual and reproductive needs. In view of this, a diagnostic study was undertaken in Uganda to understand the sexual and reproductive health needs of HIV positive adolescents and how these could be integrated into existing HIV/AIDS treatment, care and support programs.

${ }^{2}$ http://allafrica.com/stories/200704180047.html; http://www.plusnews.org/Report.aspx?ReportId=74259 


\section{Study objectives}

- To better understand the desires, intentions, experiences, beliefs, values, practices, anxieties or fears that HIV+ adolescents have around fertility, growing up, love and loving, dating, pregnancy, fatherhood, motherhood, relationships and intimacy.

- To review existing HIV/AIDS treatment, care and support programs and identify information and services gaps on family planning for HIV+ adolescents.

- To identify possible solutions for addressing sexual and reproductive health needs of HIV positive adolescents.

\section{Methodology}

The study adopted an exploratory design using a combination of quantitative, qualitative and ethnographic approaches. The target was a representative sample of adolescents who:

- Had been living with HIV since infancy, that is, who were presumed to be perinatally infected;

- Were aged 15-19 years;

- Were aware of their HIV sero-status and had disclosed it;

- Were willing and able to talk about their inner lives.

The participants were identified and recruited from April $20^{\text {th }}$ to July $21^{\text {st }} 2007$ through existing HIV/AIDS treatment, care and support programs/centers in four districts (Kampala, Wakiso, Masaka and Jinja) selected by TASO where it was felt the study could be carried out. Out of a total of 740 young people identified as eligible, two refused to participate while six participated but did not complete the interviews ${ }^{3}$. An additional 48 young people were identified to participate in focus group discussions while 12 adolescents (four of whom also participated in the survey) were identified for in-depth interviews and ethnographic case stories.

Ethical clearance for the study was granted by the TASO Internal Review Board, the Uganda National Council of Science and Technology (UNCST), the Population Council's Institutional Review Board, and the District Health Officers for Jinja, Masaka, Kampala and Wakiso.

Data were collected from 20 sites and/or HIV/AIDS treatment centers (see Table 1 below). The research team obtained clearance from the management of the centers/facilities who authorized the data clerks/officers to avail client registers to the researchers. The data clerks assisted with identifying clients aged 15-19 years. The counselors then helped with identifying the adolescent clients who were presumed or recorded as perinatally infected. From the list of those presumed to be perinatally infected, the counselors identified those to whom HIV sero-positivity had been disclosed for inclusion in the study. The researchers sought consent from parents/guardians and from the adolescents themselves for all non-emancipated persons aged 15-17 years. However, no parental/guardian consent was sought for those aged 18 and 19 years and emancipated minors aged 15-17 years.

\footnotetext{
${ }^{3}$ The reasons for not completing the interviews included inability to complete the interview due to emotion and researchers strongly doubting the respondent's perinatal infection status.
} 
Table 1: HIV/AIDS treatment, care and support centers/facilities visited in each district

\begin{tabular}{|c|c|c|}
\hline District & Facility name & Number of facilities \\
\hline Kampala & $\begin{array}{l}\text { Nsambya Home Care - Nsambya Hospital } \\
\text { Ggaba (Nsambya Home Care Outreach) } \\
\text { Kamwokya Christian Community Caring Centre } \\
\text { Kampala City Council Clinic - Kawaala } \\
\text { Kampala City Council Clinic - Kawempe } \\
\text { Mengo Home Care - Mengo Hospital } \\
\text { Namung'oona Orthodox Hospital } \\
\text { Rubaga Home Care - Rubaga Hospital } \\
\text { TASO - Mulago }\end{array}$ & 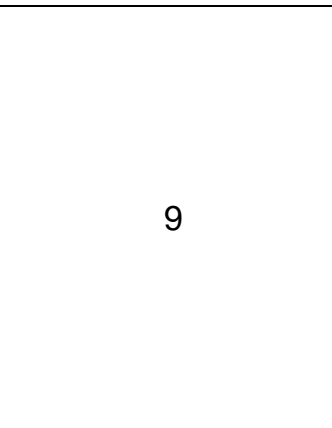 \\
\hline Masaka & $\begin{array}{l}\text { TASO - Masaka } \\
\text { Uganda Cares - Masaka } \\
\text { Villa Maria Home Care - Villa Maria Hospital }\end{array}$ & 3 \\
\hline Jinja & $\begin{array}{l}\text { Jinja Hospital } \\
\text { Buwenge Health Center } \\
\text { Nalufenya Children's Hospital } \\
\text { Nkokonjeru Hospital } \\
\text { TASO - Jinja } \\
\text { St. Francis Health Center }\end{array}$ & 6 \\
\hline Wakiso & $\begin{array}{l}\text { TASO - Entebbe } \\
\text { Mildmay Center }\end{array}$ & 2 \\
\hline \multicolumn{2}{|l|}{ Total } & 20 \\
\hline
\end{tabular}

A structured questionnaire was used to collect information in the survey while interview guides for individual in-depth discussions and group discussions were used to collect ethnographic information. The information collected included background characteristics, access to information and support for the HIV positive adolescents, sexual behavior and practices, preventive knowledge and practices, contraceptive knowledge and use, pregnancy and childbearing experiences, and issues of self-esteem, worries and sexual and physical violence.

A stakeholder analysis was also undertaken using unstructured interview questions administered to 23 key informants from governmental institutions, private organizations, non-governmental organizations, health development partners and technical assistance agencies (Table 2). The interviews focused on availability of national and institutional policy guidelines on adolescent sexual and reproductive health (SRH), the content of counseling training and services, how SRH concerns of HIV positive adolescents are handled within existing services, and whether existing programs have the capacity to handle SRH concerns of HIV positive adolescents.

Data entry and descriptive analyses were undertaken SPSS. The results are presented separately by sex and for both sexes combined. The qualitative data were transcribed and typed in Word, then emerging themes were identified and codes developed in Excel. 
Table 2: List of key informants by institutions

\begin{tabular}{|l|c|}
\hline \multicolumn{1}{|c|}{ Nature and name of institution } & $\begin{array}{c}\text { Number of } \\
\text { respondents }\end{array}$ \\
\hline Bilateral institutions & $\mathbf{3}$ \\
World Health Organization (WHO) & 1 \\
United Nations Children's Fund (UNICEF) & 1 \\
United Nations Population Fund (UNFPA) & 1 \\
\hline Line ministries and national-level institutions & $\mathbf{8}$ \\
Uganda AIDS Commission & 1 \\
Ministry of Health (Reproductive Health Unit) & 3 \\
Ministry of Gender, Labour and Social Development & 3 \\
Ministry of Education and Sports & 1 \\
\hline AlDS Information Centre (AIC) & $\mathbf{1 2}$ \\
Mildmay & 1 \\
Naguru Teenage Information and Health Centre & 1 \\
Strengthening HIV Counsellor Training in Uganda (SCOT) & 3 \\
The AIDS Support Organization (TASO) & 1 \\
Uganda Network of Young People with HIV and AIDS & 4 \\
Uganda Young Positives & 1 \\
\hline Total & 1 \\
\hline
\end{tabular}

\section{The policy environment}

There are several policies related to adolescent SRH in Uganda which, if fully implemented, would create a supportive environment for addressing the SRH needs of young people living with HIV. These policies include the National Policy Guidelines and Service Standards for Sexual and Reproductive Health and Rights (Ministry of Health, 2006), the National Adolescent Health Policy, the National Health Policy, the National Policy on Young People and HIV AIDS, and the Sexual and Reproductive Health Minimum Package for Uganda. ${ }^{4}$ The National Policy Guidelines and Service Standards for Sexual and Reproductive Health and Rights (MoH, 2006), for instance, defines adolescent SRH as one of the components of reproductive health and considers sexuality as a central aspect of being human. It provides for family planning and contraceptive service delivery as a component of reproductive health, with the objective to increase access to quality, affordable, acceptable and sustainable family planning services to everyone who needs them.

The document explicitly emphasizes adolescents and individuals or couples infected with HIV among the priority groups. Moreover, no verbal or written consent is required from parent, guardian or spouse before an adolescent client can be given family planning services. It further stipulates that in order to promote informed choice, all clients seeking contraceptives should be given adequate information about all methods available in the country. It recommends the use of dual protection -- use of a condom and another family planning method-- to protect against

\footnotetext{
${ }^{4}$ See AYA (2001) for a review of these and other related policies.
} 
HIV/AIDS and pregnancy. It also provides for the use of emergency contraception (EC) or other methods of contraception to prevent unintended pregnancies following unprotected sexual intercourse or rape. Adolescents are also recognized as a priority group with respect to ante-natal and post-natal care services as well as issues regarding sexual and gender-based violence (SGBV). Wide-ranging information is supposed to be given during ante-natal/post-natal visits, including prevention of STI/HIV, warning signs of pregnancy complications, responsible parenthood, care of the new born, nutrition, and immunization.

\section{Service provision}

Despite the favorable and elaborate policy environment for providing services to all adolescents, regardless of their sero status, addressing the broad SRH concerns of HIV-positive adolescents within existing services is weak. This is complicated further by services being mainly organized around pediatric and adult care. In particular, most young people living with HIV receive their treatment, care and support through pediatric care clinics and a few receive services through adult care clinics. Either way, the tendency has been to handle young people living with HIV as if they were young children. Most treatment and care support programs want HIV-infected young people to remain asexual. The counselors interviewed indicated that they usually discourage perinatally infected adolescents from engaging in sexual intercourse (see the excerpts below). This suggests that the health workers and counselors' capacity and understanding of the SRH needs of HIV-positive adolescents is still limited and needs to be addressed.

"You are already stigmatized and not supposed to have any sexual feeling and it is wrong for you to have that because you are going to infect all the others." (Counselor, Kampala)

"We still emphasize abstinence but these girls come here when they are pregnant and sometimes disappear for fear of facing their counselors. ” (Counselor, Masaka)

In addition, a few HIV/AIDS care and treatment centers including TASO, Naguru Teenage and Information Center, Aids Information Centre (AIC) and Mildmay Centre, have sought to integrate family planning concerns into treatment, care and support services for their clients. Most programs, including Mildmay and TASO, have family planning services as an add-on activity rather than as an integral component of other on-going activities. The lack of true service 'integration' is further undermined by a narrow method mix, especially limited to condoms and pills. With respect to antenatal services, many key informants reported that their treatment centers refer clients to other health facilities for these services. This also undermines quality of care, since referral of HIV clients to other services conflicts with the need for continuity of care, usually desired by people facing chronic conditions such as HIV/AIDS (Hekkink et al, 2003).

Although some service facilities have incorporated child counseling into their treatment, care and support package, this falls short of mentioning sexuality issues. It also fails to empower young people living with HIV with the necessary information to enable them balance rights and responsibilities, make informed decisions about their lives and contribute to their quality of life in general. Many program officials and informants explicitly recognized sexuality issues for perinatally infected adolescents as a key intervention area. Nonetheless, this recognition seems to be more due to the urgency of problems such as the increasing number of pregnancies registered 
among clients than to the inherent capacity and desire of the programs to provide information on sexuality issues to this group. This is because many programs lack institutional capacity and adequately trained staff to develop, deliver and sustain meaningful interventions pertaining to the sexuality of young people perinatally infected with HIV. Without proper training, service providers may share the values and biases of the larger society. They may, for instance, feel extremely uncomfortable discussing sexuality issues with young people.

With respect to institutional capacity, many informants indicated that HIV/AIDS care and treatment centers are increasingly overwhelmed by large numbers of clients. As one counselor from Kampala stated, "The major issue I see here is that the client-counselor ratio is so high... Therefore, at times the quality may be compromised by the number of people. Because we have so many people to see, you may not actually have this close contact with the client. You may not handle all the issues that the client has." Many program officials also reported that they usually undertake a wide-range of activities, so that service providers are left with very limited or no time to focus on sexuality issues. Moreover, there are limited opportunities available within existing programs to access professional training in sexuality and relevant disciplines (AYA, 2003). Where training is available, the curricula are silent on or provide limited coverage of sexuality issues. The TASO Trainers Manual (TASO, 2005), for instance, hardly includes sexuality-related aspects-- the entire 109-page manual is silent on notions of sex and sexuality, except where it mentions sexual abuse and sexually transmitted infections.

With this type of content available in the curriculum and training manuals, counselors undoubtedly lack the capacity to find out about young people's sexuality desires and reproductive health needs. While it is important for curricula to address issues such as HIV transmission, prevention, sero-status disclosure, life skills, parenting/ guardianship and positive living, talking about positive living without embracing issues of sexuality can leave most young clients unprepared for practicing safer sexual behaviors and satisfying their sexual lives. Moreover, it may inhibit disclosure of their HIV status to potential and existing partners.

There are, however, some positive developments toward addressing the reproductive and sexual health needs of young people living with HIV. First, the MoH Strengthening Counselor Training (SCOT) program is currently developing a prototype curriculum that will facilitate capacity building among service providers to handle adolescence issues. Second, addressing sexuality is not emerging in a vacuum. A few programs, such as the Program for Enhancing Adolescent Health (PEARL) in the Ministry of Gender Labour and Social Development (MGLSD) and the Family Planning Association of Uganda (FPAU), already have curricula covering some aspects of sexuality for adolescents. PEARL also has a manual for trainers of peer mobilizers, the contents of which include key aspects such as HIV/AIDS/STIs, contraceptive use, emergency contraception, abstinence, post-abortion care, sexuality relationships and life skills (AYA, 2003). The training curriculum for FPAU also covers contraceptives, information and education about reproductive health, male participation, reproductive system, peer education and life skills. The Uganda Youth Development Link (UYDL) has a guide for training street children peer counselors which also covers human sexuality, sex and sexuality, life skills and income generation. Thirdly, the coverage of sexuality issues in the electronic and print media also provides reason for optimism. Though overall media coverage on issues of sexuality is still 
limited (AYA, 2003), it increasingly provides opportunities to transmit relevant sexuality information to perinatally HIV-infected adolescents.

In sum, wide programmatic gaps exist in addressing the sexual and reproductive health needs of young people perinatally infected with HIV transitioning into adolescence and adulthood. The existing policy environment provides an opportunity that is yet to be matched with implementation strategies, including relevant training curricula for service providers. Overall, there is limited scope and capacity for addressing sexuality issues in current HIV/AIDS care programs. Even with a strengthened curriculum, how service providers and counselors understand and interpret SRH counseling for HIV-positive adolescents will still be important. Structural constraints reflected in the inadequate supply regimes such as the limited method mix and inadequate capacity to handle SRH concerns of HIV-positive adolescents due to lack of skilled personnel can be resolved within the existing policy framework.

\section{Characteristics of perinatally infected adolescents}

About two-thirds of the respondents (64 percent) were females, perhaps reflecting the fact that in Uganda, as elsewhere in sub-Saharan Africa, women are disproportionately affected by and infected with HIV than men. It could also partly be due to gender differences in survival during childhood and teenage years as well as in health-seeking behaviors. In particular, it could be that HIV positive females are more likely to survive childhood and teenage years than HIV positive males or it could be that females are more likely to seek care than males.

Table 3: Distribution of survey respondents by other background characteristics

\begin{tabular}{|c|c|c|c|}
\hline Characteristics & $\begin{array}{l}\text { Female } \\
(\mathrm{N}=469)\end{array}$ & $\begin{array}{c}\text { Male } \\
(\mathrm{N}=263)\end{array}$ & $\begin{array}{c}\text { Both } \\
(\mathrm{N}=732)\end{array}$ \\
\hline \multicolumn{4}{|l|}{ Aqe qroup } \\
\hline $15-17$ years & $60 \%$ & $57 \%$ & $59 \%$ \\
\hline 18-19 years & $40 \%$ & $43 \%$ & $41 \%$ \\
\hline \multicolumn{4}{|l|}{ District } \\
\hline Jinja & $21 \%$ & $32 \%{ }^{* \pi}$ & $25 \%$ \\
\hline Kampala & $29 \%$ & $24 \%$ & $27 \%$ \\
\hline Wakiso & $35 \%$ & $18 \%$ & $29 \%$ \\
\hline Masaka & $15 \%$ & $26 \%$ & $19 \%$ \\
\hline \multicolumn{4}{|l|}{ School attendance } \\
\hline In-school & $71 \%$ & $71 \%$ & $71 \%$ \\
\hline Out of school & $29 \%$ & $29 \%$ & $29 \%$ \\
\hline \multicolumn{4}{|l|}{ Living arrangements } \\
\hline Lives with parents & $31 \%$ & $35 \%$ & $33 \%$ \\
\hline Doesn't live with parents/N/A & $69 \%$ & $65 \%$ & $67 \%$ \\
\hline \multicolumn{4}{|l|}{ Parents' living arrangements } \\
\hline Living together & $9 \%$ & $11 \%$ & $9 \%$ \\
\hline Divorced/separated & $7 \%$ & $4 \%$ & $6 \%$ \\
\hline Mother dead & $14 \%$ & $16 \%$ & $15 \%$ \\
\hline Father dead & $23 \%$ & $21 \%$ & $22 \%$ \\
\hline Both parents dead & $47 \%$ & $48 \%$ & $47 \%$ \\
\hline \multicolumn{4}{|l|}{ Employment status } \\
\hline Has a paid job & $11 \%$ & $19 \%{ }^{* \pi}$ & $14 \%$ \\
\hline Has no paid job & $89 \%$ & $81 \%{ }^{* *}$ & $86 \%$ \\
\hline
\end{tabular}

HH- Household; N/A- not applicable; Percentages may not add up to exactly 100 in some cases due to rounding error; Differences between males and females are significant at: ${ }^{*} \mathrm{p}<0.05 ;{ }^{* *} \mathrm{p}<0.01$ 
More than half of the respondents (59 percent) were young (aged 15-17 years) ${ }^{5}$ and more than two-thirds (71 percent) were attending school at the time of the survey (Table 3 ). Older adolescents were more likely than younger ones to be out of school. Only one in three of the respondents lived with at least one of the parents while almost half of the respondents had lost both parents (Table 3). Those who were not living with parents lived with either guardians, especially relatives including aunties, uncles, grandparents, and elder siblings, or with spouses. Two in three of the respondents lived with five or more people while the vast majority (90 percent) reported that they had siblings though they were not necessarily living with them.

\section{Information and support}

Respondents were asked whether they ever discussed with parents / guardians and service providers issues related to sexuality such as dating and relationships, how pregnancy occurs, methods of birth control, having children and sex. About one-third of the respondents discussed these issues with parents or guardians. At the same time, almost twice as many adolescents indicated that they had ever talked with service providers than with parents about these issues (Table 4). In contrast, more than 60 percent of adolescents indicated that they had ever talked to parents/guardians and service providers about other aspects of life such as hopes about self, fears in life, and living life as a young person with HIV.

Table 4: Percentage of respondents who ever talked with parents/guardians and service providers

\begin{tabular}{|l|cc|cc|}
\hline & \multicolumn{2}{|c|}{ Parent/guardian } & \multicolumn{2}{c|}{ Service provider/counselor } \\
\hline Aspect talked about: & $\begin{array}{c}\text { Female } \\
\text { (N=469) }\end{array}$ & $\begin{array}{c}\text { Male } \\
\text { (N=263) }\end{array}$ & $\begin{array}{c}\text { Female } \\
\text { (N=469) }\end{array}$ & $\begin{array}{c}\text { Male } \\
\text { (N=263) }\end{array}$ \\
\hline Menstruation & $64 \%$ & $\mathrm{~N} / \mathrm{A}$ & $54 \%$ & $\mathrm{~N} / \mathrm{A}$ \\
Dating and relationships & $38 \%$ & $21 \%{ }^{* *}$ & $55 \%$ & $56 \%$ \\
How pregnancy occurs & $44 \%$ & $19 \%{ }^{* *}$ & $60 \%$ & $53 \%$ \\
Method of birth control & $32 \%$ & $24 \%{ }^{*}$ & $51 \%$ & $54 \%$ \\
Having/not having children & $40 \%$ & $26 \%{ }^{* *}$ & $52 \%$ & $53 \%$ \\
Sex & $43 \%$ & $27 \%$ & $67 \%$ & $65 \%$ \\
Hopes & $72 \%$ & $67 \%$ & $67 \%$ & $72 \%$ \\
Fear & $64 \%$ & $68 \%$ & $63 \%$ & $73 \%{ }^{* *}$ \\
Living life as a young person & $64 \%$ & $62 \%$ & $78 \%$ & $71 \%{ }^{*}$ \\
Wet dreams & $\mathrm{N} / \mathrm{A}$ & $15 \%$ & $\mathrm{~N} / \mathrm{A}$ & $36 \%$ \\
Body size & $43 \%$ & $25 \%{ }^{* *}$ & $40 \%$ & $36 \%$ \\
Masturbation & $4 \%$ & $6 \%$ & $9 \%$ & $21 \%{ }^{* *}$ \\
\hline
\end{tabular}

N/A- not asked; Differences between males and females are significant at: ${ }^{*} \mathrm{p}<0.05 ;{ }^{* *} \mathrm{p}<0.01$.

Respondents were also asked whether they found it easy to talk to their health service providers/ counselors about things that are important to them. More than four in five adolescents found it easy to talk to service providers, with females (83\%) significantly less likely to report this than males $(90 \%)$. Younger and older adolescents found it easy to talk to the service providers ( 85

5 Throughout this report younger respondents or adolescents refer to 15-17 year-olds while older adolescents refer to $18-19$ year-olds. 
percent and 87 percent respectively). Qualitative data also indicate that many adolescents found it easy to talk to service providers to the extent that most of them had attained a parent-child relationship. Whereas this type of relationship was convivial, it would seem that sometimes providers would find it difficult because of cultural norms to talk about sexuality issues with a 'daughter' or 'son', which probably explains why 15 percent of respondents found it difficult to talk to service providers.

Adolescents living with HIV also need support services or support groups where they are likely to meet each other. The following quote from one of the support groups illustrates this need:

"You know, after disclosure, some of our friends lose hope, they look worried... So we took it upon ourselves as a group to meet our fellow adolescents living with HIV so that we could give them courage. We tell them that it is not the end of their life and give them hope, counsel them..." (FGD 4, Unique Sisters' group)

Only 26 percent reported belonging to a support group, with no significant difference between males and females. Figure 1 indicates that that several categories of support groups emerged, the most predominant ones being orphanage centers, health facility/HIV centers and clubs for people having HIV. Jajja's homes, Our Generation of Mildmay Adolescents Clients (OGMAC), TASO Youth Clubs, Shadow Idol and Vision Club were the most frequently mentioned support groups.

Figure 1: Percentage of respondents who belong to particular types of support groups

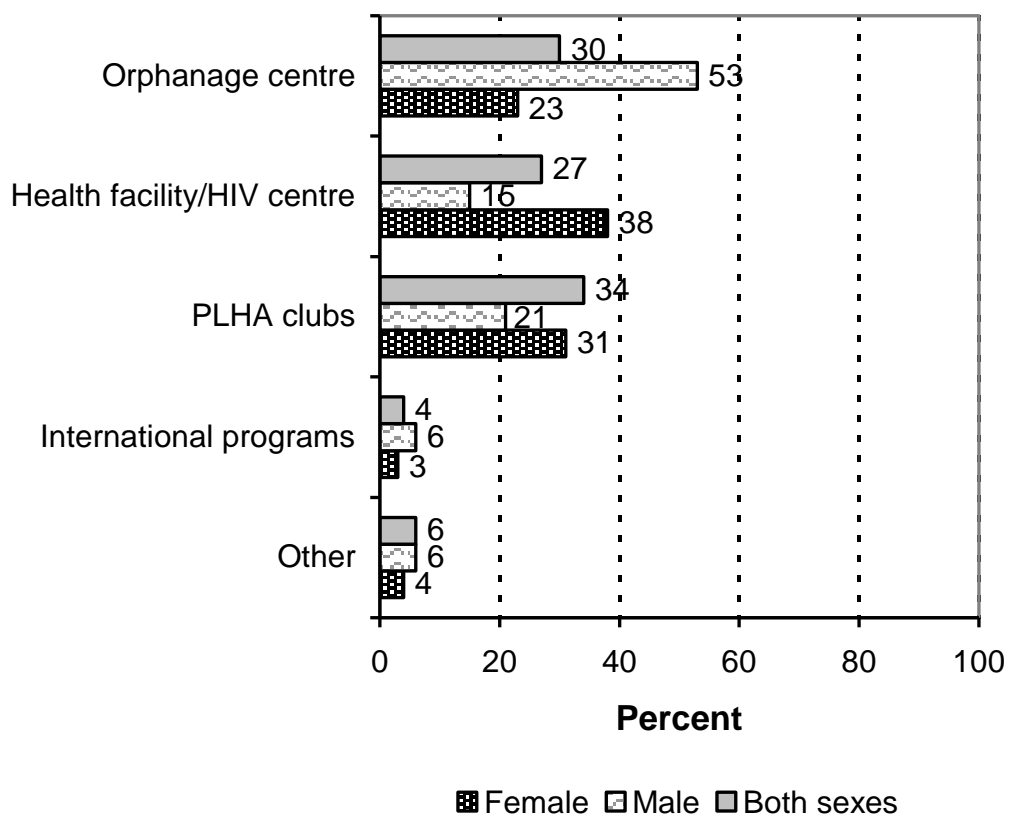

The support groups provide peer support, life skills education and psychosocial support. The adolescents felt that the support groups and clubs help them share and know that they are not alone, as well as gain knowledge of others who could be worse off than themselves. Through support groups, adolescents also receive peer support in making informed decisions regarding 
sexual practices. Some of the groups, such as OGMAC, also provide forums where adolescents can meet and discuss a range of issues about AIDS with their parents/guardians.

Qualitative data, however, suggest that most existing support groups are weak and need strengthening. For example, adolescents complained that OGMAC is not age-sensitive as it brings together children from the age range of eight to 17 years, yet these have different interests. The support groups were also criticized for their limited range of life skills and failure to follow up on the members' activities. Adolescents further felt that parents and guardians were not adequately encouraging them to participate in support group activities.

\section{Sexual behavior and practices}

Young people living with HIV are beginning to explore their sexuality by dating and sharing intimacy despite advice from service providers that they refrain from or postpone sexual initiation. This is illustrated by the following case:

"My mother and the counselors always tell me what to do but I listen to them and later do my own things because I believe I am old enough to make my own decisions... It is all about love now!" (Female, Ethnographic Case Study No. 10, Masaka)

About one half (52\%) of respondents were currently in a relationship, mostly non-married but with about five percent in a marital or long-term relationship (Figure 2). A substantial proportion of those in relationships $(64 \%)$ had no intention to marry while one-third considered the relationships important and could lead to marriage.

\section{Figure 2: Distribution of respondents by whether they are currently in sexual partnership}

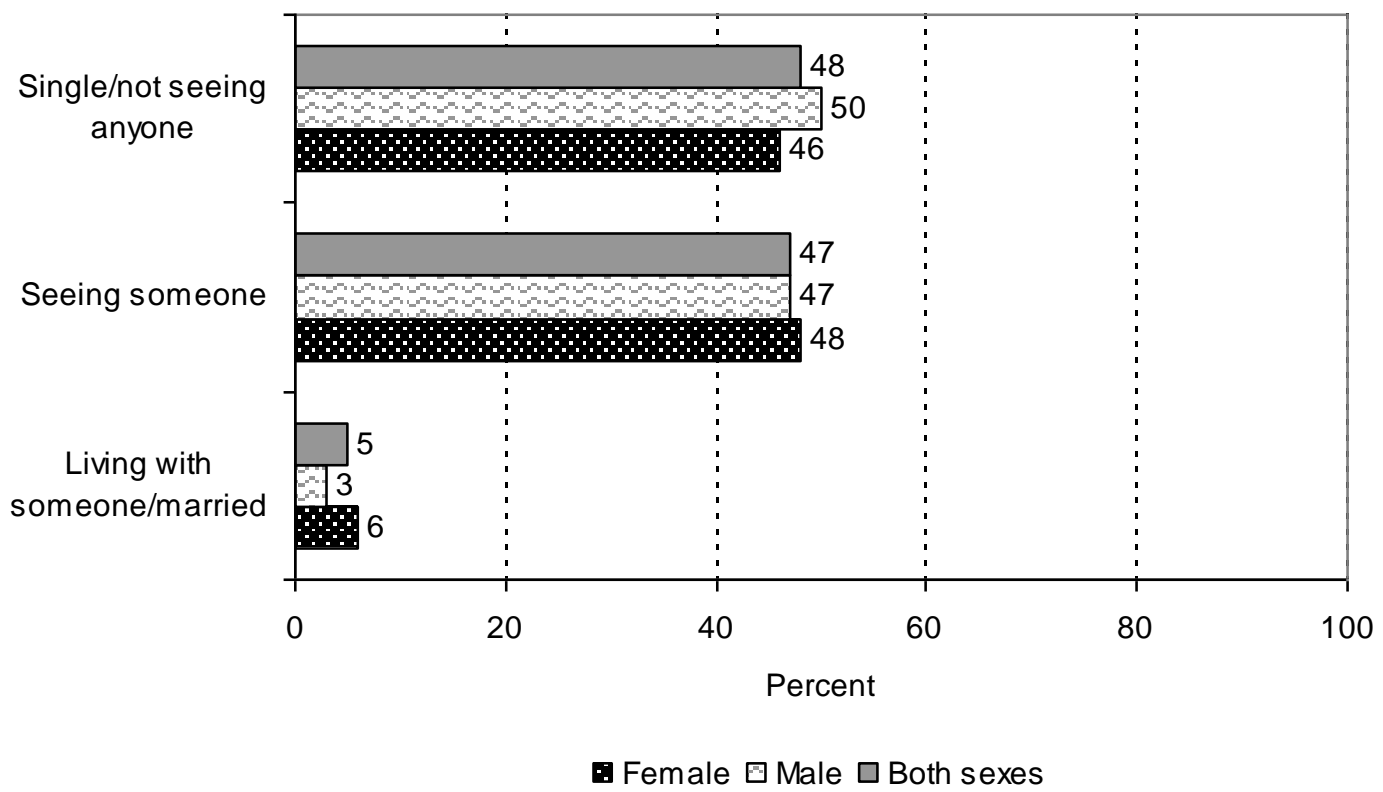


Half of the respondents had ever fantasized about love and sex, and about one-third had ever engaged in kissing and touching (Table 5). Significantly more adolescent males than females $(\mathrm{p}<0.01)$ had ever engaged in touching or fantasizing about love and sex. One-third of the respondents had started having sex. Of these, 73 percent had consensual first sex. One in 10 of those who had initiated sex did so by age 10, while 74 percent had first sex between 11 to 16 years, which is similar to the general population of adolescents as reported by the Uganda HIV/AIDS Sero-Behavioral Survey 2004-2005 (MOH and ORC Macro 2006).

Qualitative data also indicate that many adolescents felt that having sex is unavoidable and abstinence from sexual intercourse is nearly impossible:

"Sex is something everyone would go for, very few can avoid it... One cannot pretend that come-what-may I will never have sex because it is natural. It is not easy to avoid it." (Male, Focus Group Discussion No. 1, Mildmay Centre)

"It is natural. Anyone who has grown to the age of having sex, he or she has to have it or seek to have it ... When one has grown to the age of 16, he or she starts feeling the need to have sex. The body simply demands it. Then what follows is to learn how to get somebody to do it with and how to do it. ... When one is growing up and his or her peers do not see him or her dating, then they start scorning him or her." (Male, Focus Group 2, TASO, Entebbe)

Table 5: Percentage of respondents who have ever engaged in particular sexual practices

\begin{tabular}{|l|c|c|c|}
\hline Sexual behavior/practice & $\begin{array}{c}\text { Female } \\
\text { (N=469) }\end{array}$ & $\begin{array}{c}\text { Male } \\
\mathbf{( N = 2 6 3 )}\end{array}$ & $\begin{array}{c}\text { Both } \\
\text { (N=732) }\end{array}$ \\
\hline Ever engaged in: & & & \\
Kissing & $31 \%$ & $34 \%$ & $32 \%$ \\
Touching & $33 \%$ & $43 \%{ }^{* *}$ & $37 \%$ \\
Fondling & $26 \%$ & $32 \%$ & $28 \%$ \\
Masturbation & $12 \%$ & $19 \%{ }^{* *}$ & $15 \%$ \\
Hugging & $43 \%$ & $58 \%$ & $48 \%$ \\
Fantasizing about love and sex & $40 \%$ & $70 \%$ & $50 \%$ \\
Sexual intercourse & $31 \%$ & $37 \%$ & $33 \%$ \\
\hline
\end{tabular}

Differences between males and females are significant at: ${ }^{*} \mathrm{p}<0.05 ;{ }^{* *} \mathrm{p}<0.01$.

\section{Preventive knowledge and practices}

Respondents were asked about what they can do to avoid re-infecting themselves with another strain of HIV. The three most commonly known ways of avoiding re-infection include abstinence (66 percent), condom use (63 percent) and avoiding sharing of skin-piercing instruments (27 percent). Significantly more adolescent males than females mentioned using condoms as a way of avoiding re-infection with HIV (Table 6). When asked about what a 
woman can do to prevent pregnancy, condom use was the most commonly known way (73 percent) followed by use of other contraceptives (50 percent). Again, significantly more adolescent males than females mentioned using condoms as a way of preventing pregnancy.

Table 6: Knowledge of ways of preventing re-infection with HIV and pregnancy

\begin{tabular}{|l|c|c|c|}
\hline \multirow{2}{*}{ Ways of prevention } & \multicolumn{3}{|c|}{ Preventing re-infection with HIV } \\
\cline { 2 - 4 } & $\begin{array}{c}\text { Female } \\
(\mathrm{N}=469)\end{array}$ & $\begin{array}{c}\text { Male } \\
(\mathrm{N}=263)\end{array}$ & $\begin{array}{c}\text { Both sexes } \\
(\mathrm{N}=732)\end{array}$ \\
\hline Abstaining & $66 \%$ & $64 \%$ & $66 \%$ \\
Using condoms & $58 \%$ & $71 \%$ & $63 \%$ \\
Not sharing skin-piercing instruments & $26 \%$ & $29 \%$ & $27 \%$ \\
\hline & \multicolumn{3}{|c|}{ Preventing pregnancy } \\
\hline Using condoms & $68 \%$ & $81 \%$ & $73 \%$ \\
Using other contraceptives & $48 \%$ & $54 \%$ & $50 \%$ \\
Periodic abstinence & $2 \%$ & $2 \%$ & $2 \%$ \\
\hline
\end{tabular}

Differences between males and females are significant at: ${ }^{*} \mathrm{p}<0.05 ;{ }^{* *} \mathrm{p}<0.01$.

There seems to be a gap, however, between knowledge of ways of prevention and actual preventive practices. Among those who had ever had sex, only about one-third (37 percent) reported using a method to prevent HIV infection or re-infection at first sex (Table 7). Similarly, among those who reported that they were currently using condoms, only $30 \%$ reported usage to prevent infecting the partner with HIV/STIs. The percentage currently using condoms to prevent re-infection with HIV was also low (25 percent). The commonest reason given for current use of condoms was for pregnancy prevention (57 percent).

Table 7: Percentage of respondents who used a method to prevention of HIV infection or pregnancy

\begin{tabular}{|l|c|c|c|}
\hline & Female & Male & Both sexes \\
\hline Used a method to prevent HIV infection/re-infection & $39 \%$ & $35 \%$ & $37 \%$ \\
at first sex & $(\mathrm{N}=138)$ & $(\mathrm{N}=98)$ & $(\mathrm{N}=236)$ \\
Currently using a condom to prevent: & $(\mathrm{N}=65)$ & $(\mathrm{N}=49)$ & $(\mathrm{N}=114)$ \\
Infecting partner with HIV/STIs & $26 \%$ & $35 \%$ & $30 \%$ \\
HIV infection & $26 \%$ & $25 \%$ & $25 \%$ \\
Pregnancy & $54 \%$ & $61 \%$ & $57 \%$ \\
\hline
\end{tabular}

Most respondents seemed to be comfortable disclosing their status to the health service provider, family member or close relative. Just over one-third of the respondents who were in a relationship (38 percent) disclosed their HIV status to their partners (Figure 3). 


\section{Figure 3: Distribution of respondents who had disclosed their HIV sero-status to significant others}

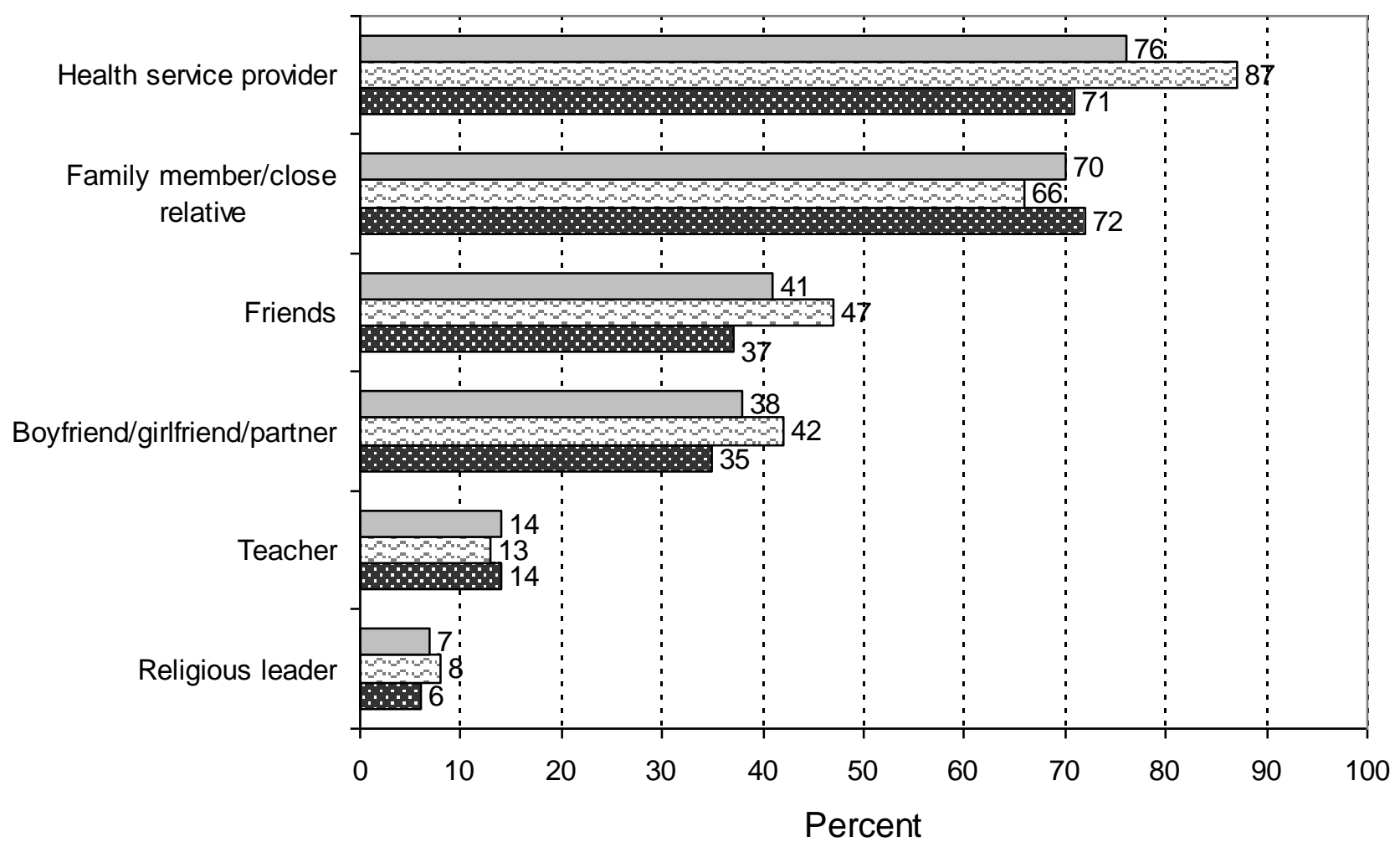

๑ Female $\square$ Male $\square$ Both sexes

Qualitative data further suggest that even in the event of disclosure, the partners do not mind having or continuing the relationship even if they are discordant as exemplified by the following excerpts:

"I asked her to leave me and find someone else-negative. She told me that she was not going to leave because of my status." (Male, Ethnographic Case Study No. 7)

"If you have a sign people may leave you alone. But if no sign, they come after you even if you tell them, they say you are lying..." (Female, Focus Group Discussion No. 5, TASO, Mulago)

"I have a boyfriend. He knows my HIV sero-status. I disclosed to him and he said that he did not mind." (Female, Focus Group Discussion No. 3) 


\section{Contraceptive knowledge and use}

Similar to the evidence from the Uganda Demographic and Health Survey (DHS), knowledge of contraceptive methods is high among adolescents. Overall, $89 \%$ of the respondents knew of at least one contraceptive method, although this was significantly higher among males (97 percent) than females ( 84 percent). The condom was the most known method, followed by the contraceptive pill (Table 8). Again, a significantly higher proportion of male than female respondents reported knowledge of the pill or condom. The emergency pill and the /IUD are practically unknown methods. However, 93 percent expressed the need for more knowledge about contraception.

Table 8: Percentage of respondents who knew of a method of contraception

\begin{tabular}{|l|c|c|c|}
\hline \multicolumn{1}{|c|}{ Method } & $\begin{array}{c}\text { Female } \\
\text { (N=372) }\end{array}$ & $\begin{array}{c}\text { Male } \\
\text { (N=238) }\end{array}$ & $\begin{array}{c}\text { Both sexes } \\
\text { (N=610) }\end{array}$ \\
\hline Contraceptive pill & $86 \%$ & $60 \%{ }^{*}$ & $76 \%$ \\
Condom & $81 \%$ & $88 \%$ & $84 \%$ \\
Injection & $54 \%$ & $15 \%{ }^{*}$ & $39 \%$ \\
Periodic abstinence & $12 \%$ & $29 \%^{*}$ & $19 \%$ \\
Withdrawal & $2 \%$ & $5 \%{ }^{*}$ & $3 \%$ \\
Coil/IUD & $2 \%$ & $5 \%{ }^{*}$ & $3 \%$ \\
Emergency pill & $1 \%$ & 0 & $1 \%$ \\
\hline
\end{tabular}

Differences between males and females are significant at: ${ }^{*} \mathrm{p}<0.05 ;{ }^{* * *} \mathrm{p}<0.01$.

Knowledge of where young people could obtain contraceptives and/or learn about contraceptives was also almost universal, with 92 percent of the respondents reporting such knowledge. Respondents were also asked about where they would feel comfortable getting a contraceptive method if they wanted - 43 percent indicated that they would prefer an HIV/AIDS care and treatment center while 27 percent would prefer a family planning clinic.

Although awareness of contraception is nearly universal, use of a method is not. This mismatch between relatively high knowledge and low use could be attributable to a lack of information about or limited supplies of contraceptives. It could also be due to prevailing misconceptions about contraceptives as illustrated by some of the adolescents' statements:

"Somebody has talked about pills. I hear that they are dangerous. Is it true that they are dangerous or not? I am asking because it seems that one might deliver a child with missing body parts. [Others giggle, especially female participants] So please explain to us." (Focus Group No. 1, Mildmay Centre)

"He does not want condoms but prefers injections or pills, which I refused since I heard that they form wounds in the uterus." (Ethnographic case study 8, TASO, Masaka)

Only one-half of those who had initiated sex had used any form of contraception in their current or previous relationship (Figure 4). Of those who were currently using a method, almost half reported consistent use. Nonetheless, this is a relatively high rate of contraceptive use for an adolescent population, perhaps suggesting more careful behavior among the HIV-infected adolescents. 


\section{Figure 4: Distribution of respondents who used any method of contraception in current or previous relationship and the frequency of current use}

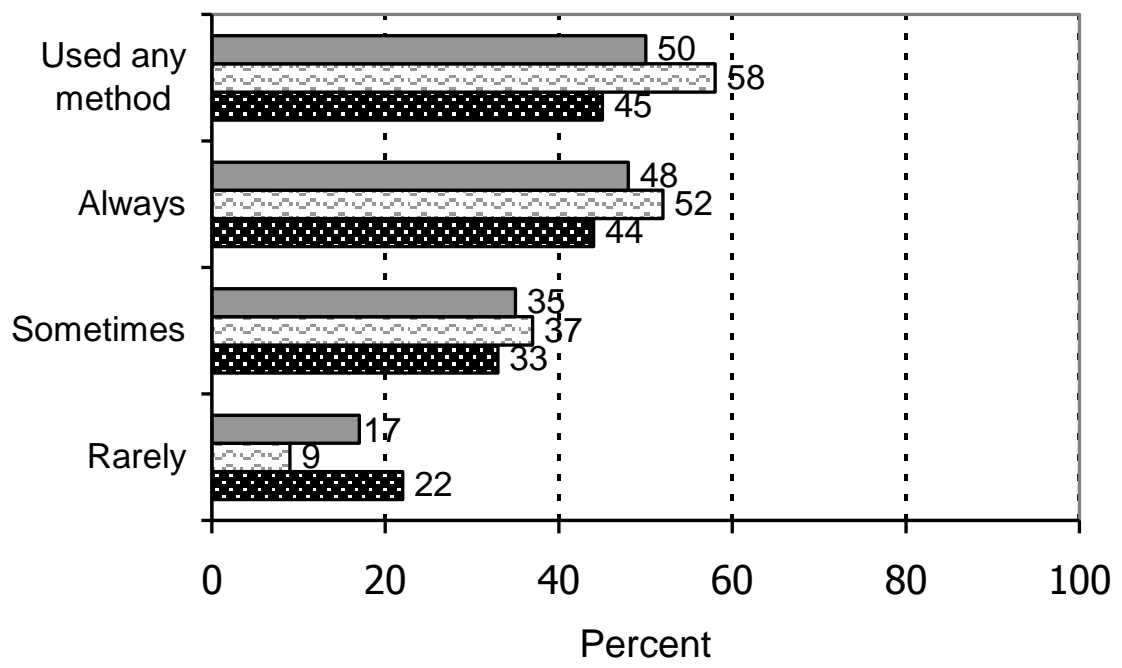

Female $\square$ Male $\square$ Both sexes

Note: Difference in use of any method between females and males is significant at $p<0.05$.

Qualitative data, however, also point to some level of inconsistent use as illustrated by the following quotes:

"It's hard...I used to use a condom with my boyfriend at first but he got tired; after some time we tried sex without a condom. I think that's when I got pregnant." (Female, Ethnographic case study 3, Nsambya Home Care)

"You know men, [after using condoms for some time] he asked me that after all that time, couldn't I trust him! I also said I would use the monthly calendar for family planning but I wasn't serious with this, that is how I became pregnant." (Female, Ethnographic case study 4, TASO, Mulago)

"I insist on using a condom with him, but most times he refuses. He forces me to have sex when am weak or not feeling well and sometimes I end up with infections." (Female, Case study No. 12, Entebbe)

\section{Pregnancy and childbearing}

Most adolescents living with HIV dream of getting married and having families of their own (Birungi et al. 2007). Several key informants acknowledged that counselors advise HIV-infected persons to avoid getting pregnant but are not heeded. For example, 41 percent of the sexually active female adolescents had ever been pregnant and almost three-quarters ( 73 percent) of them delivered the child (Table 9). Less than 20 percent of sexually active adolescent males reported having ever impregnated a girl, and for half of those who had done so their partners kept the pregnancy. 
Table 9: Percentage of sexually active young people by pregnancy experience and decisions taken

\begin{tabular}{|l|c|c|}
\hline Pregnancy experience/decision taken & Female & Male \\
\hline Ever impregnated/been pregnant* $^{*}$ & $41 \%$ & $16 \%$ \\
Mean number of times impregnated/been pregnant ${ }^{* *}$ & $(\mathrm{~N}=144)$ & $(\mathrm{N}=98)$ \\
Decision taken regarding pregnancy ${ }^{* *}$ & 1.3 & 1.1 \\
Kept it & $(\mathrm{N}=60)$ & $(\mathrm{N}=16)$ \\
Ended it & $73 \%$ & $50 \%$ \\
Miscarried & $13 \%$ & $38 \%$ \\
Still pregnant & $7 \%$ & $13 \%$ \\
\end{tabular}

*Among those who had ever had sex

** Among those who have ever been pregnant or impregnated a girl

The desire to have children and families is also shown by the fact that more than two-thirds (69 percent) of the adolescents who already had children intend to have more in the future (Table 10). Likewise, more than four-fifths ( 86 percent) of those who did not have children intend to have them in future. The majority ( 88 percent) of those who had no children but who intend to have them in future would, however, like to do so later in life (Table 10).

Table 10: Intention to have children in future

\begin{tabular}{|l|c|c|c|}
\hline \multicolumn{1}{|c|}{ Fertility intention } & Female & Male & $\begin{array}{c}\text { Both } \\
\text { sexes }\end{array}$ \\
\hline Percentage of those who have children who intend to have & $65 \%$ & $87 \%$ & $69 \%$ \\
more & $(\mathrm{N}=60)$ & $(\mathrm{N}=15)$ & $(\mathrm{N}=75)$ \\
Percentage of those who do not have children who intend to & $83 \%$ & $92 \%$ & $86 \%$ \\
have them in future & $(\mathrm{N}=405)$ & $(\mathrm{N}=248)$ & $(\mathrm{N}=653)$ \\
How soon those who do not have children would like to have & & & \\
them & $(\mathrm{N}=334)$ & $(\mathrm{N}=228)$ & $(\mathrm{N}=562)$ \\
$\quad$ Very soon & $8 \%$ & $2 \%$ & $6 \%$ \\
$\quad$ Later in life & $87 \%$ & $89 \%$ & $88 \%$ \\
Not decided & $5 \%$ & $9 \%$ & $6 \%$ \\
\hline
\end{tabular}

The desire to have children in future is also supported by qualitative data:

"I do not want to become a mother at this stage. I need to complete my studies first and then get a man of my life who can take care of both the child and me in future." (Female, Focus Group Discussion No. 1, Mildmay Centre)

"After my studies I would wish to get somebody who is aware of my HIV status and so should she be. Besides, I also think about having children but I cannot have them except when my counselors are ready to help me. You know, it needs the counselor's help so that the child and I do not get affected." (Female, Focus Group Discussion No. 3, Kampala Christian Caring Centre) 


\section{Self-esteem}

Young people living with HIV do not primarily construct their lives around their illness but appear to have their concerns constructed around a better life in the future, their looks, and around issues of dating and loving (Birungi et al. 2007). The majority of the respondents (65 percent), for instance, want to be professional scientists, medical doctors, lawyers and entrepreneurs. Almost half (46 percent) want to be well-educated and prosperous in future and look forward to achieving these dreams. Only slightly more than one-third were worried about being HIV positive, perhaps, because this is a condition they have lived with since infancy. Almost one in six adolescents were worried about their friends mistreating them, being rejected or not being able to find a boyfriend or girlfriend. Worries about illness revolved around disclosing their HIV status to friends, people finding out that they live with HIV and infecting someone else with HIV (Table 11).

Table 11: Percent distribution of respondents worried about various aspects of life

\begin{tabular}{|l|c|c|c|}
\hline \multicolumn{1}{|c|}{ Aspect worried about: } & $\begin{array}{c}\text { Female } \\
\text { (N=469) }\end{array}$ & $\begin{array}{c}\text { Male } \\
\text { (N=263) }\end{array}$ & $\begin{array}{c}\text { Both } \\
\text { (N=732) }\end{array}$ \\
\hline Friends mistreating them or being rejected & $21 \%$ & $8 \%{ }^{* *}$ & $16 \%$ \\
Not being able to find a girlfriend/boyfriend & $18 \%$ & $15 \%$ & $17 \%$ \\
Being chucked by boyfriend/girlfriend & $29 \%$ & $31 \%$ & $30 \%$ \\
Personal looks & $18 \%$ & $19 \%$ & $18 \%$ \\
Being HIV positive & $36 \%$ & $38 \%$ & $37 \%$ \\
Disclosing their HIV sero status to friends & $54 \%$ & $44 \%{ }^{* *}$ & $51 \%$ \\
Becoming pregnant or causing pregnancy & $74 \%$ & $75 \%$ & $74 \%$ \\
People finding out that they live with HIV & $57 \%$ & $47 \%{ }^{* *}$ & $54 \%$ \\
Infecting someone else with HIV & $83 \%$ & $75 \%{ }^{* *}$ & $80 \%$ \\
Body not developing as fast as friends' & $25 \%$ & $27 \%$ & $26 \%$ \\
Having sex & $60 \%$ & $32 \%{ }^{* *}$ & $50 \%$ \\
Being forced to do sexual things they don't want & $73 \%$ & $41 \%{ }^{* *}$ & $61 \%$ \\
\hline
\end{tabular}

Differences between males and females are significant at: ${ }^{*} \mathrm{p}<0.05 ;{ }^{* *} \mathrm{p}<0.01$.

\section{Discussion and programmatic implications}

The findings of this situation analysis are intended to provide a better understanding the sexual and reproductive health concerns of adolescents perinatally infected with HIV, and to this information to identify and develop interventions that integrate SRH issues for such adolescents into the existing HIV/AIDS treatment, care and support programs that serve them. A key finding is that perinatally infected people aspire to live their lives just like their peers who are not HIVinfected. This study confirms that there exist wide programmatic gaps in addressing the sexual and reproductive health needs of young people perinatally infected with HIV who are now growing into adolescents and adults. This evidence provides, therefore, a concrete basis for generating discussions on how existing programs could be strengthened to provide young people 
with appropriate information and services. Involvement of HIV positive adolescents in the development of any interventions will be critical. Some of the recommendations for programmatic actions that can be made from these findings are as follows:

Strengthen preventive services: Sexually active HIV positive adolescents need appropriate information to prevent unwanted pregnancies and HIV transmission. HIV/AIDS treatment centers will need to improve provision of information and services for family planning and HIV prevention for the adolescents that they serve, as the study found that these services are generally weak or non-existent and that adolescents indicated a preference for obtaining contraceptive services from such centers. HIV care and treatment centers need to start assessing the contraceptive needs of HIV positive adolescents and consistently provide an appropriate method mix.

Making pregnancy safer for HIV positive adolescents: 41 percent of sexually active female adolescents have experienced a pregnancy (our study did not investigate their pregnancy outcomes). Effective PMTCT services are a critical component of ANC for pregnant HIV positive adolescents to reduce the likelihood of vertical transmission. In particular, HIV/AIDS treatment centers should be able to identify pregnant adolescents early and ensure that they are referred to receive a full range of ANC and PMTCT services.

Involve parents to openly discuss sexuality: Barely one-third of adolescents reported having ever talked with their parents/guardians about dating and sex. Programs will need to establish mechanisms that encourage parents to open up and discuss these issues with adolescents.

Re-orient HIVIAIDS service providers/counselors: Whereas service providers/counselors are more likely to talk about sexuality than parents / guardians, service providers tend not to offer balanced counseling. More often than not they tend to provide warning messages instead of practical information, guidance and support. They also tend to develop a parent-child type of relationship, to the extent that some adolescents are unwilling to disclose their sexual and reproductive health desires and needs, and also pregnancies when they occur. Programs need to provide training and reorientation to help existing HIV/AIDS providers/counselors undertake their work without becoming "parents" to their adolescent clients. HIV/AIDS counselors would benefit from an assessment tool that they could use as a checklist to determine relevant items to discuss with HIV positive adolescents during counseling sessions. Such a tool could help the provider/counselor to systematically assess adolescents for their sexual and reproductive health information and service needs, and to address them immediately and/or offer appropriate referral. In addition, existing counseling and support training packages will need to be updated to include information on sexual and reproductive health needs for HIV positive adolescents.

Establish transition clinics: Some of the existing care centers are not age-sensitive as they bring together children throughout the age range of eight to 17 years. Some of the adolescents transiting to early adulthood are not willing to obtain services from the adult care centers and yet they no longer comfortable in the pediatric clinic setting. HIV/AIDS treatment centers should therefore consider setting up transition clinics to cater for older HIV positive adolescents. Related to this, HIV/AIDS treatment centers may need to consider putting in place adolescentfriendly service providers and counselors whose ages are comparable with those of the clients. 
Strengthen support groups: Many HIV positive adolescents belong to support groups, which are a potential channel for reaching these adolescents with critical sexual and reproductive health information. However, the existing support groups and clubs are weak and so programs will need to provide training and support to their leaders for them to become sustainable and responsive to the needs of the members.

Improve life skills for HIV positive adolescents to: 1) understand their sexuality as they grow; 2) practically deal with the identity of being HIV positive at an early age and negotiate vital aspects of their lives, especially disclosing their status; 3 ) enjoy positive lifestyles and avoid undesired consequences such as unintended pregnancies and infection of others; and 4) make informed choices and balance responsibility with sexual and reproductive desires.

In conclusion, adolescents perinatally infected with HIV have the same aspirations as those who are not HIV-infected. This study confirms that wide programmatic gaps exist in addressing the sexual and reproductive health needs of young people perinatally infected with HIV who are now growing into sexually active adolescents and adults. This evidence provides a concrete basis for generating discussions on how existing HIV/AIDS programs will have to change to provide young people with information and services 


\section{References}

AYA (2003) Final report of on the rapid fact finding study (situation analysis) on adolescent and reproductive health in Uganda, K2-Consult Uganda Limited.

Birungi H., Mugisha J.F., and Nyombi J.K (2007) "Sexuality of young people perinatally infected with HIV: A neglected element in HIV/AIDS Programming in Uganda", Exchange on HIV/AIDS, sexuality and gender. 2007.3.

Fielden, S., Sheckter, L., Chapman, G., Aliment, A., Forbes, J., Sheps, S., Cadell S., and Frankish J. (2006) "Growing up: perspectives of children, families and service providers regarding needs of older children with perinatally-acquired HIV", AIDS Care, November 2006; 18 (8): 1050-1053.

Hekkink, C., Sixma, H., Wigersma, L., Yzermans, C., van der Meer, J. and Bindels, P.(2003) "QUOTE-HIV: an instrument for assessing quality of HIV care from the patients' perspective”, Qual Saf Health Care 2003;12:188-193

http://allafrica.com/stories/200704180047.html

http://www.plusnews.org/Report.aspx?ReportId=74259

Kirumira, E. (1996) Familial relationships and population dynamics in Uganda: A case study of fertility behaviour in the Central Region. PhD Thesis, University of Copenhagen.

Ministry of Health (2006) The National Policy Guidelines and Service Standards for Sexual and Reproductive Health and Rights, Kampala, Uganda

Ministry of Health (MOH) [Uganda] and ORC Macro. 2006. Uganda HIV/AIDS SeroBehavioural survey 2004-2005, Calverton, Maryland, USA: Ministry of Health and ORC Macro

Regional Centre for Quality of Health Care (RCQHC) (2003) Report on the Regional Workshop on Early Diagnosis and Care of HIV-infected Children, March 31- April 2003, Kampala, Uganda

The AIDS Support Organization [TASO] (2005) TASO Trainers manual, TASO, 2005

Rice, E., Batterham P., and Rotherram-Borus, M. (2006) “Unprotected sex among youth living with HIV before and after the advent of highly active antiretroviral therapy" Perspectives on Sexual and Reproductive Health, Volume 38, Number 3

World Health Organization (2006) Sexual and reproductive health of women living with HIV/AIDS: Guidelines on care, treatment and support for women living with HIV/AIDS and their children in resource-constrained settings WHO: Geneva 


\section{FOR MORE INFORMATION, CONTACT:}

Frontiers in Reproductive Health

Population Council

4301 Connecticut Avenue, N.W.

Suite 280

Washington, D.C. 20008

USA

Telephone: $\quad$ 202-237-9400

Facsimile: 202-237-8410

E-mail: frontiers@pcdc.org

Website: $\quad$ www.popcouncil.org

AfricA

Population Council Regional Office

P.O. Box 17643

Nairobi

Kenya

Telephone: $\quad$ 254-2-2713480/1/2/3

Facsimile: $\quad$ 254-2-2713479

E-mail: $\quad$ publications@pcnairobi.org

Asia AND the Near EAst

Population Council Regional Office

Ground Floor, Zone 5A

India Habitat Center

Lodi Road

New Delhi 110003

India

Telephone: 91-11-461-0913

Facsimile: $\quad 91-11-464 \backslash 2903$

E-mail: $\quad$ frontiers@pcindia.org

Latin America AND the CARIBbeAn

Population Council Regional Office

Escondida 110

Villa Coyoacan

04000 Mexico, D.F.

Mexico

Telephone:

52-5-659-8537

Facsimile:

52-5-554-1226

E-mail:

disemina@popcouncil.org.mx

\section{Population Council}

The Population Council is an international, nonprofit, nongovernmental institution that seeks to improve the well-being and reproductive health of current and future generations around the world and to help achieve a humane, equitable, and sustainable balance between people and resources. The Council conducts biomedical, social science, and public health research and helps build research capacities in developing countries. Established in 1952, the Council is governed by an international board of trustees. Its New York headquarters supports global network of regional and country offices.

\section{FRONTIERS \\ IN REPRODUCTIVE HEALTH}

FRONTIERS is funded by the Office of Population of the UNITED STATES AGENCY FOR INTERNATIONAL DEVELOPMENT (USAID) under the terms of Cooperative Agreement Number HRN-A-00-98-00012-00 